\title{
STRATEGI IMPLEMENTASI \& OPTIMALISASI MANAJEMEN ENERGI DI PT SEMEN PADANG SEBAGAI UPAYA KEUNGGULAN BERSAING DI INDUSTRI PERSEMENAN NASIONAL
}

\author{
Arief Rahman Dasril ${ }^{(1)}$ \\ Universitas Andalas \\ arrahmand@gmail.com \\ Syukri Lukman ${ }^{(2)}$ \\ Universitas Andalas
}

\begin{abstract}
Energy is a determining factor in the company's efforts to be superior in the national cement industry competition. If we look at the factor of total production costs COGM (Cost Of Goods Manufactured) in the last five years, the portion of energy costs always occupies the top position with a percentage of $45 \%$ - 52\% of the total cost of cement production. Therefore, in order to win the competition in the cement industry, it is necessary to manage energy consumption more effectively and efficiently. This study aims to determine the contribution of the implementation energy management system at PT Semen Padang as an effort to reduce energy consumption in the cement production process. The results of this study indicate that the implementation of the energy management system at PT Semen Padang has a significant impact on reducing energy consumption and increasing the company's competitive advantage so that it has an impact on increasing the bottom line of PT Semen Padang.
\end{abstract}

Keyword : Competitive Advantage, Energy Management, Firm Performance, Cement Industry 


\section{PENDAHULUAN}

Pertumbuhan PDB (Produk Domestik Bruto) nasional yang tinggi, mencapai rata-rata $6,04 \%$ per tahun selama periode 2017-2050, diperkirakan akan semakin mendorong peningkatan kebutuhan energi Indonesia di masa depan. Oleh karena itu pemakaian energi harus diatur sedemikian rupa selain untuk ketahanan energi indonesia juga sebagai upaya untuk mengendalikan emisi rumah kaca secara global. (BPPT, Outlook Energi Indonesia, 2018)

Jika kebutuhan energi yang didominasi oleh bahan bakar fosil (energi tidak terbarukan) terus meningkat tanpa ada perubahan pola pemakaian energi, maka keberlangsungan dan ketahanan energi Indonesia akan terganggu. Selain itu, komitmen penurunan emisi gas rumah kaca Indonesia yang tercantum dalam First Nationally Determined Contribution, yaitu sebesar 29\% atau 314 juta ton $\mathrm{CO} 2 \mathrm{e}$ (unconditional) dan sebesar $41 \%$ atau 398 juta ton $\mathrm{CO} 2 \mathrm{e}$ (conditional) pada tahun 2030 juga bisa sulit tercapai.

Untuk diketahui kebutuhan energi sampai saat ini hingga tahun 2050 terus meningkat sesuai dengan pertumbuhan ekonomi, penduduk, harga energi, dan kebijakan pemerintah. Dengan laju pertumbuhan PDB rata-rata sebesar $6,04 \%$ per tahun dan pertumbuhan penduduk sebesar $0,71 \%$ per tahun selama tahun 2016-2050 mengakibatkan laju pertumbuhan kebutuhan energi final sebesar 5,3\% per tahun. Untuk itu, kebutuhan energi meningkat dari 795 juta SBM (Setara Barrel Minyak) pada tahun 2016 menjadi 4.569 juta SBM pada tahun
2050. Pada tahun 2050, pangsa kebutuhan energi final terbesar adalah bahan bakar minyak (BBM) yakni sebesar 40,1\%, diikuti oleh listrik $(21,3 \%)$, gas $(17,7 \%)$, batubara $(11,0 \%)$, dan sisanya LPG, bahan bakar nabati (BBN) dan biomassa masing-masing di bawah 4\%. (BPPT, Outlook Energi Indonesia, 2018)

Kesadaran tentang konservasi energi nasional harus ditanamkan di semua lini karena dengan pemakaian energi yang efektif dan efesien akan memberikan keuntungan seperti semakin meningkatnya transfer teknologi, mengurangi impor minyak dan meningkatkan ketahanan energi nasional. Hal ini perlu diperhatikan secara serius karena pemakaian energi yang tidak terbarukan meningkat setiap tahun tanpa ada penambahan sumber energi baru akan menguras cadangan energi di indonesia.

Meningkatnya pemakaian energi global beberapa dekade ini memberikan dampak terjadinya perubahan secara radikal, emisi karbon dioksida yang dihasilkan dari berbagai industri akan memberikan ancaman serius terhadap iklim dunia (Schuster, 2012). PT Semen Padang merupakan salah satu industri semen yang besar di indonesia dengan kapasitas 10,4 juta Ton semen pertahun. Untuk menghasilkan semen sebanyak itu tentu membutuhkan energi yang sangat besar.

Jika dilihat dari faktor biaya produksi COGM (Cost Of Goods Manufactured) maka porsi biaya energi menempati posisi teratas dengan 
persentase sebanyak sebanyak $45 \%$ $52 \%$ dari total biaya produksi semen. Oleh karena itu untuk memenangkan persaingan di industri persemenan yang semakin ketat dari tahun ke tahun maka pengelolaan energi yang efektif dan efesien harus menjadi fokus utama dari manajemen, karena pengehematan energi sebanyak $1 \%$ - 5\% akan memberikan dampak yang signifikan bagi perusahaan dan akan membuat perusahaan menjadi lebih kompetitif untuk bersaing dengan industri persemenan dalam negri.

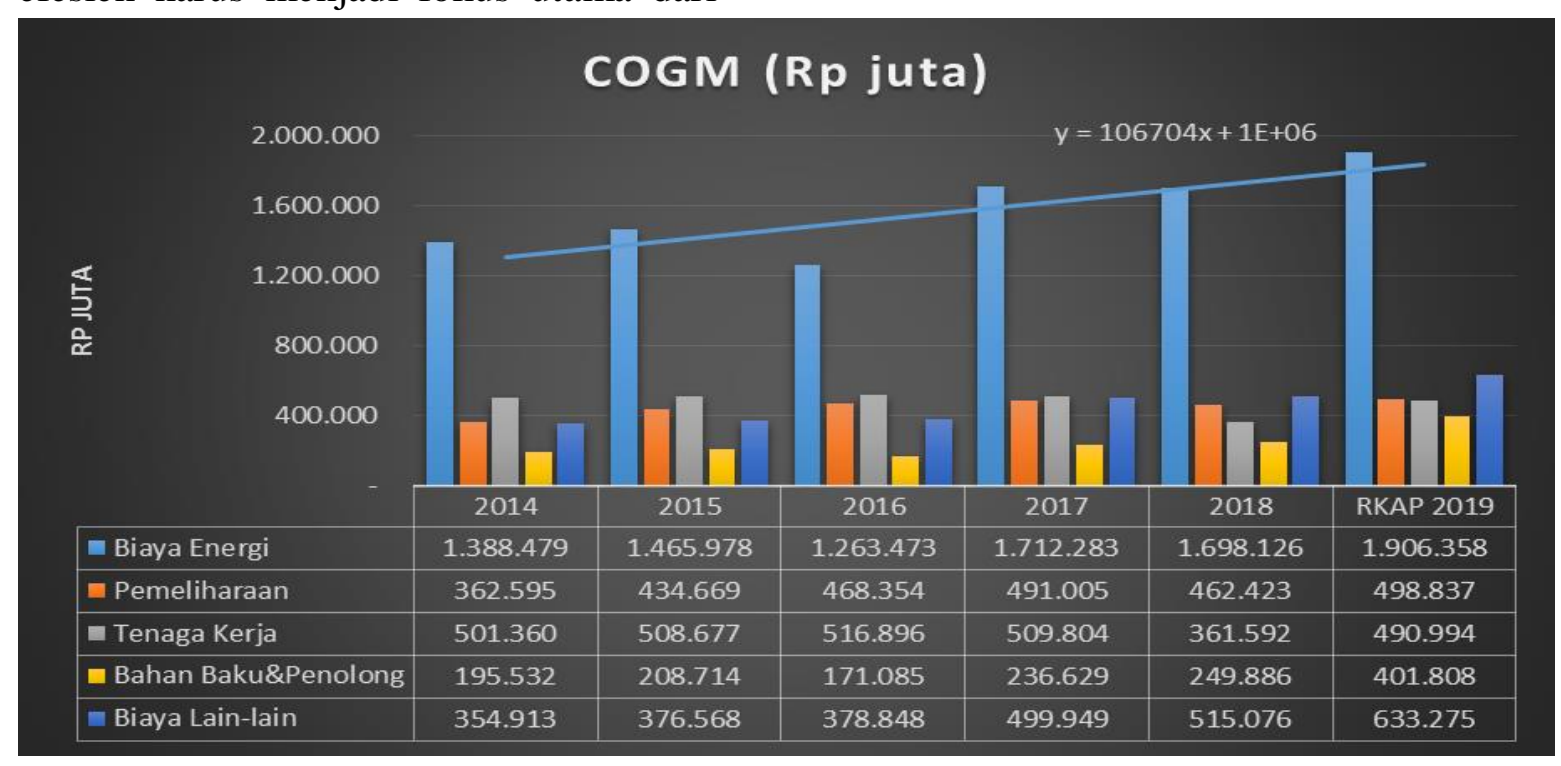

Gambar 1 Grafik Kenaikan Biaya Energi dari Tahun 2014-2019

Belum adanya penelitian yang meneliti terkait pengelolaan energi di PT Semen Padang membuat peneliti tertarik untuk melihat seberapa jauh Implementasi Manajemen Energi di PT

\section{TINJAUAN TEORI}

Pada zaman sekarang, energi merupakan kebutuhan vital bagi kehidupan manusia yang secara berkelanjutan dan penggunaannya ada disetiap tempat sehingga menjadi faktor penting bagi pertumbuhan ekonomi di setiap negara. Manajemen energi memiliki fungsi untuk mengatur dan memonitor pemakaian energi dan saat ini menjadi isu yang sangat besar pada setiap negara. Aktifitas manajemen meliputi analisis, konservasi energi dan tindakan yang berkesinambungan yang mengarah kepada minimalisasi kehilangan energi
Semen Padang dalam memberikan penghematan dalam konsumsi energi listrik dan termal dalam rangka mendukung grand strategi perusahaan yaitu cost leadership strategy.

\section{Manajemen Energi}

(losses) untuk meningkatkan efesiensi dan berfokus kepada pemanfaatan energi baru dan terbarukan (L.A. Tiago, 2017).

Manajemen Energi memiliki tujuan untuk melindungi lingkungan dengan membatasi perilaku yang menyebabkan perubahan iklim yang diakibatkan oleh pembakaran yang bersumber dari bahan bakar fosil. Oleh karena itu manajemen energi sebenarnya mengidentifikasi dan mencari tau peluang penghematan energi dengan cara mengontrol dan memonitoring pemakaaian energi (Carlos Alvarez, 2004) 
Mengacu kepada ISO 50001 manajemen energi adalah suatu elemen yang saling terkait dan berinteraksi untuk membuat suatu tujuan dan kebijakan yang berhubungan dengan energi (Catherine Cooremans, 2019). Berdasarkan defenisi ini terlihat bahwa manajemen energi merupakan suatu sistem yang memiliki tujuan untuk perbaikan yang berkelanjutan bagi perusahaan. Performa energi diukur menggunakan tools dan alat ukur yang berkaitan dengan konsumsi energi, pemanfaatan energi dan efesiensi energi

\section{Program Manajemen Energi}

Mengubah cara pengelolaan energi di suatu industri dengan cara mengimplementasikan Program Manajemen Energi merupakan suatu cara yang cukup sukses dan efektif dalam membawa improvement pada pemanfaatan energi yang lebih efesien. Program manajemen energi yang kuat sangat dibutuhkan untuk menciptakan pondasi sistem agar tercipta perubahan positif dan sebagai pedoman dalam pengelolaan energi di suatu organisasi. Program manajemen energi ini tidak hanya memastikan terjadinya improvement sesaat saja tetapi lebih kepada improvement berkelanjutan. Oleh karena itu program manajemen energi ini sangat butuh dukungan dari top manajemen, karena tanpa dukungan dari jajaran top manajemen maka program manajemen energi ini tidak akan bisa meraih hasil yang optimal. (Galitsky, 2008)

Pada suatu perusahaan yang tidak memiliki program energi yang jelas akan membuat kesempatan untuk improvement akan berkurang karena adanya hambatan organisasi. Hambatanhambatan tersebut mungkin tercipta akibat kurangnya komunikasi antar divisi, lemahnya pemahaman akan pentingnya efesiensi energi di suatu perusahaan, dan terbatasnya kondisi keuangan perusahaan. Meskipun demikian walaupun mereka tau bahwa energi ini berpengaruh secara signifikan terhadap perusahaan masih banyak perusahaan yang abai terhadap hal ini dikarenakan kurangnya komitmen yang kuat untuk menjalankan program manajemen energi ini.

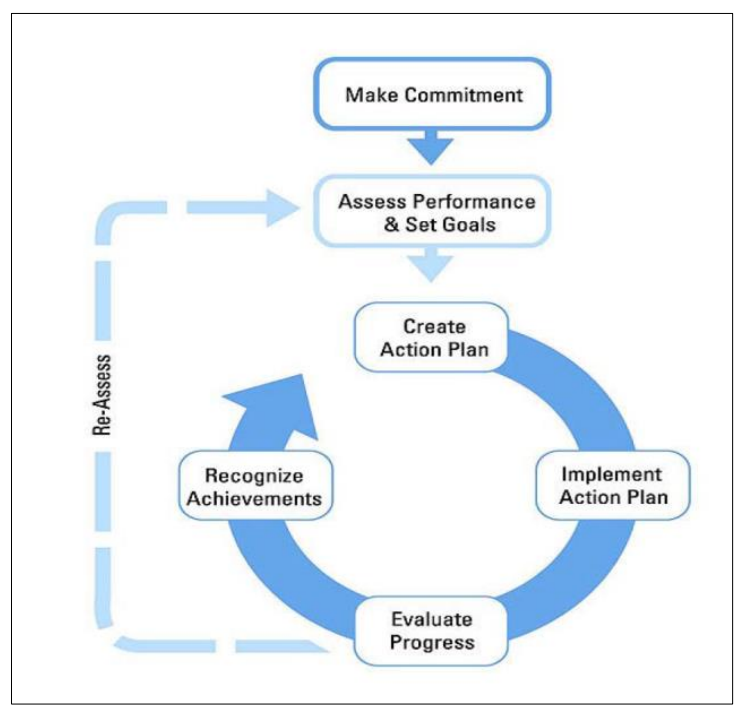

Gambar 2 Elemen Utama Program

\section{Manajemen Energi Strategis (Galitsky,} 2008)

Pada gambar diatas ini ditampilkan elemen utama dalam menjalankan program manajemen energi strategis, kesuksesan program manajemen energi ini dimulai dengan adanya komitmen suatu organisasi/perusahaan yang kuat terhadap improvement berkelanjutan terkait dengan efesiensi energi, dalam mendukung komitmen tersebut maka harus dilakukan beberapa aktifitas yaitu

1. Membuat kebijakan energi di organisasi / perusahaan

2. Membentuk tim energi lintas fungsional

3. Melakukan assesment secara regular terhadap peformance energy yang significant. Suatu organisasi / perusahaan dapat menetapkan sendiri baseline energi mereka berdasarkan 
data-data yang ada kemudian menetapkan sasaran dan tujuan yang ingin dicapai. Dengan adanya sasaran dan tujuan maka akan membantu perusahaan untuk mengembangkan dan mengimplementasikan rencana aksi yang telah dibuat.

\section{Benchmarking}

Aspek penting yang harus diperhatikan untuk memastikan rencana aksi sukses diimplementasikan adalah personil yang terlibat. Setiap personil di semua level jabatan harus menyadari terkait isu energi dan tujuan dari efesiensi energi. Staff harus diberikan pelatihan baik dari skill maupun pemahaman terkait praktek efesiensi energi dilapangan. Kemudian hasil dari pelaksanaan aktifitas tersebut harus dievaluasi secara reguler dan dikomunikasikan keseluruh personil yang terlibat.

Evaluasi terhadap progress dilakukan secara reguler terhadap data energi dan aktifitas yang merupakan bagian dari rencana aksi. Informasi yang dikumpulkan selama proses review ini akan membantu dalam menyeting tujuan dan sasaran yang akan dicapai. Menciptakan program komunikasi yang kuat akan membantu terciptanya dukungan dan momentum yang akan bermanfaat bagi aktifitas di masa yang akan datang

\section{METODE PENELITIAN}

Pada penelitian ini akan dilakukan analisis data secara kuantitatif. Data didapatkan dari laporan keuangan dan laporan produksi yang dikeluarkan oleh yang dikeluarkan oleh unit akuntansi dan unit perencanaan produksi setiap bulan. Data yang diperlukan antara lain yaitu (1) Data konsumsi energi listrik untuk masing-masing pabrik di PT Semen Padang, (2) data konsumsi bahan bakar masing-masing pabrik di PT Semen Padang, (3) data troubleshooting tiap pabrik, dan (4) data penyusun COGM semen 5 (lima) tahun terakhir serta datadata terkait lainnya.

Kemudian data-data energi yang diperoleh di analisis dengan cara menentukan baseline energi terlebih dahulu, fungsi dari baseline energi ini adalah pedoman/patokan apakah pemakaian energi yang digunakan hemat atau boros. Setelah baseline didapat tahap selanjutnya adalah menentukan cusum (Cumulative Summary) untuk menghitung jumlah saving / losses yang didapat selama periode Mei 2019 - Sept 2019 dimana implementasi manajemen energi ini mulai dilakukan di PT Semen Padang. 
Tabel 1

Baseline dan Performance Energi Listrik PT Semen Padang

\begin{tabular}{|l|l|l|l|r|l|}
\hline Plant & Equipment & Regression & $R^{2}$ & Konsumsi Energi Dari Mei-Sept 2019 \\
\hline Indarung 4 & $4 \mathrm{~W} 1$ & $\mathrm{y}=47,334 \mathrm{x}+701551$ & $\mathrm{R}^{2}=0,9303$ & $-544.645 \mathrm{kWh}$ & Hemat \\
\hline Indarung 4 & $4 \mathrm{Z1}$ & $\mathrm{y}=28,545 \mathrm{x}+756479$ & $\mathrm{R}^{2}=0,788$ & $-875.420 \mathrm{kWh}$ & Hemat \\
\hline Indarung 4 & $4 \mathrm{Z2}$ & $\mathrm{y}=18,889 \mathrm{x}+861803$ & $\mathrm{R}^{2}=0,7792$ & $79.747 \mathrm{kWh}$ & Boros \\
\hline Indarung 4 & $4 \mathrm{R} 1$ & $\mathrm{y}=8,7651 \mathrm{x}+1 \mathrm{E}+06$ & $\mathrm{R}^{2}=0,8207$ & $3.101 .376 \mathrm{kWh}$ & Boros \\
\hline Indarung 4 & $4 \mathrm{R} 2$ & $\mathrm{y}=14,861 \mathrm{x}+398584$ & $\mathrm{R}^{2}=0,7612$ & $-253.105 \mathrm{kWh}$ & Hemat \\
\hline Indarung 5 & $5 \mathrm{~W} 1$ & $\mathrm{y}=33,056 \mathrm{x}+2 \mathrm{E}+06$ & $\mathrm{R}^{2}=0,9337$ & $-1.433 .130 \mathrm{kWh}$ & Hemat \\
\hline Indarung 5 & $5 Z 1$ & $\mathrm{y}=36,835 \mathrm{x}+387163$ & $\mathrm{R}^{2}=0,8744$ & $665.558 \mathrm{kWh}$ & Boros \\
\hline Indarung 5 & $5 \mathrm{Z2}$ & $\mathrm{y}=34,055 \mathrm{x}+200500$ & $\mathrm{R}^{2}=0,9857$ & $-59.164 \mathrm{kWh}$ & Hemat \\
\hline Indarung 5 & $5 \mathrm{R} 1$ & $\mathrm{y}=15,978 \mathrm{x}+311552$ & $\mathrm{R}^{2}=0,9235$ & $-419.984 \mathrm{kWh}$ & Hemat \\
\hline Indarung 5 & $5 \mathrm{R} 2$ & $\mathrm{y}=16,272 \mathrm{x}+333076$ & $\mathrm{R}^{2}=0,8993$ & $-470.489 \mathrm{kWh}$ & Hemat \\
\hline Indarung 6 & $6 \mathrm{~W} 1$ & $\mathrm{y}=27,969 \mathrm{x}+873722$ & $\mathrm{R}^{2}=0,8833$ & $-1.825 .316 \mathrm{kWh}$ & Hemat \\
\hline Indarung 6 & $6 \mathrm{R} 1$ & $\mathrm{y}=22,532 \mathrm{x}+15517$ & $\mathrm{R}^{2}=0,9182$ & $-2.706 .274 \mathrm{kWh}$ & Hemat \\
\hline Indarung 6 & $6 \mathrm{Z1}$ & $\mathrm{y}=25,907 \mathrm{x}+496116$ & $\mathrm{R}^{2}=0,9302$ & $415.466 \mathrm{kWh}$ & Boros \\
\hline
\end{tabular}

Tabel 2

Baseline dan Performance Energi Listrik PT Semen Padang

\begin{tabular}{|l|l|l|l|r|l|}
\hline Plant & Equipment & Regression & $\mathbf{R}^{\mathbf{2}}$ & \multicolumn{2}{|c|}{ Konsumsi Energi Dari Mei-Sept 2019 } \\
\hline Indarung 4 & Kiln Ind 4 & $\mathrm{y}=1100,5 \mathrm{x}+6 \mathrm{E}+09$ & $\mathrm{R}^{2}=0,9754$ & 2.675 .411 .973 Kcal & Boros \\
\hline Indarung 5 & Kiln Ind 5 & $\mathrm{y}=982,67 \mathrm{x}+1 \mathrm{E}+10$ & $\mathrm{R}^{2}=0,9607$ & -4.610 .415 .627 Kcal & Hemat \\
\hline Indarung 6 & Kiln Ind 6 & $\mathrm{y}=1284,9 \mathrm{x}-2 \mathrm{E}+10$ & $\mathrm{R}^{2}=0,9756$ & -11.742 .302 .257 Kcal & Hemat \\
\hline
\end{tabular}

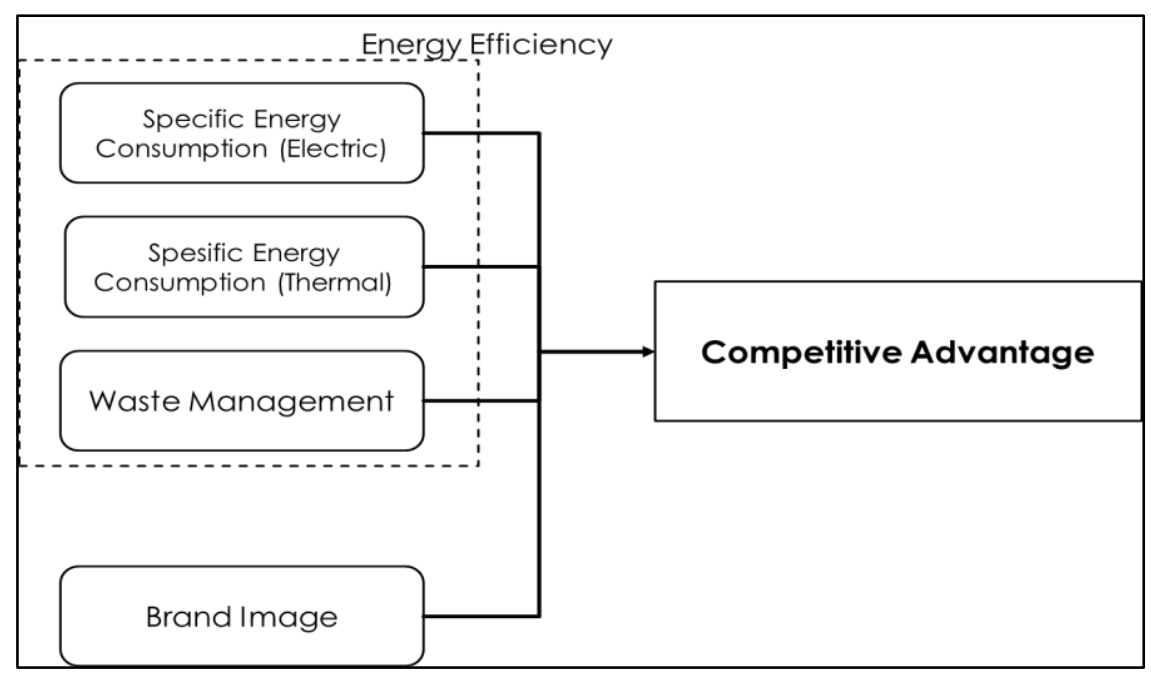

Gambar 3

Model Kerangka Penelitian 


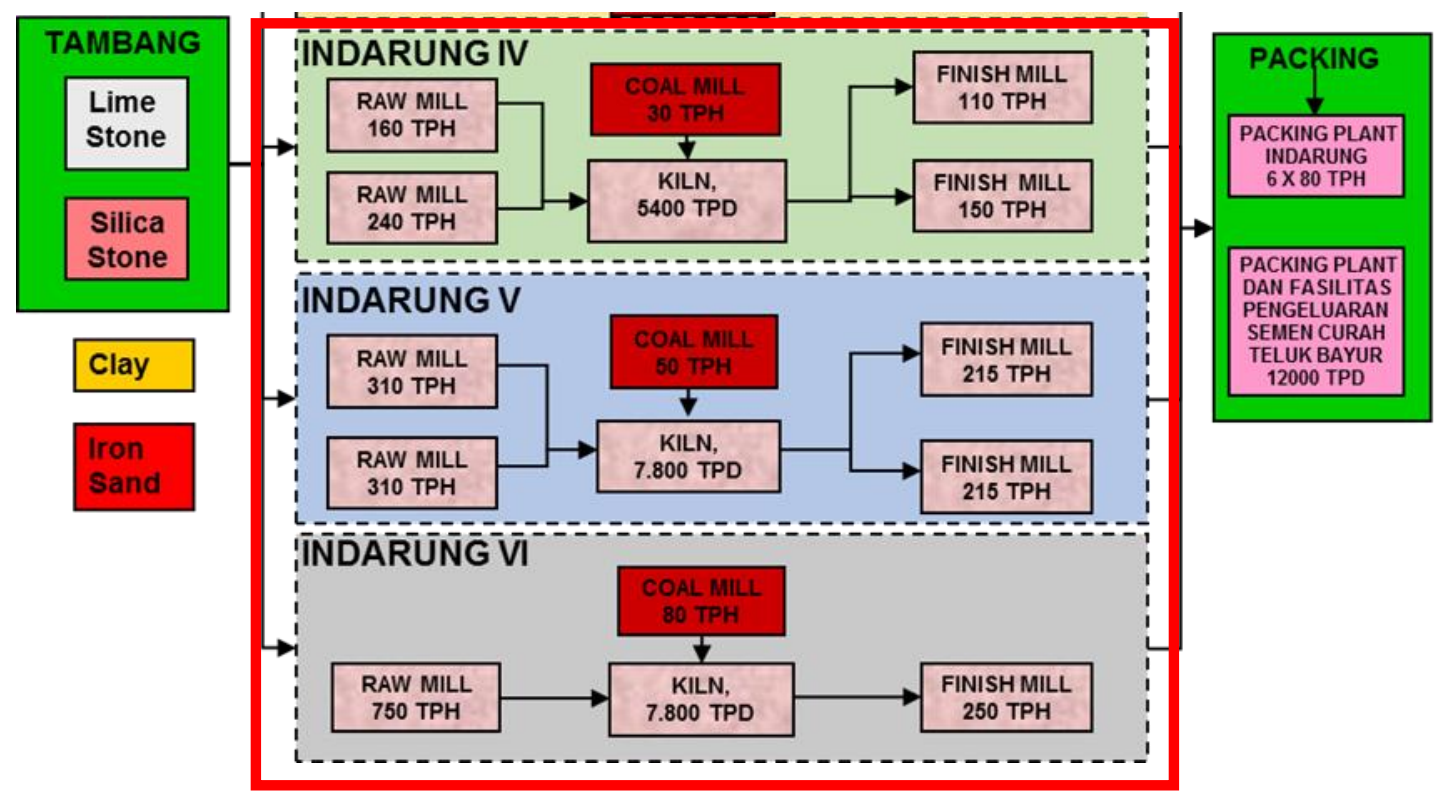

Gambar 4

Batasan Penelitian Pada Area Pabrik Indarung 4, 5 dan 6

\section{HASIL DAN PEMBAHASAN}

Dengan diterapkannya sistem manajemen energi dari Bulan Mei 2019 Sept 2019 memberikan penghematan dari pemakaian energi listrik sebesar 5.141.030 kWh atau sebesar Rp 5,12 miliar dengan asusmi $1 \mathrm{kWh}=\mathrm{Rp} 997$ dan penghematan energi termal 13.677.305.910 Kcal atau sebesar Rp 1,66 miliar untuk pabrik Indarung IV, Indarung $\mathrm{V}$ dan Indarung VI dengan asumsi nilai kalori rata-rata batubara yang dipakai sebesar $4.600 \mathrm{Kcal} / \mathrm{Kg}$ dengan harga sebesar Rp 560.000 / ton batubara.

Dengan implementasi sistem manajemen energi di PT Semen Padang dalam lima bulan terakhir perusahaan telah berhasil melakukan penghematan sebesar Rp 6,79 miliar yang dihitung dari konsumsi energi untuk Pabrik Indarung 4, Indarung 5 dan Indarung 6. atau sebesar $0,172 \%$ dari total biaya produksi PT Semen Padang berdasarkan RKAP 2019 dan sebesar $0,356 \%$ dari total biaya energi berdasarkan RKAP 2019 
Tabel 3

Saving Energi Listrik dan Termal Level 2 untuk Raw Mill, Kiln dan Finish Mill

\begin{tabular}{|c|c|c|c|c|c|c|c|c|}
\hline \multirow{2}{*}{ PLANT } & \multicolumn{8}{|c|}{ KONSUMSI ENERGI DARI MEI 2019 - SEPT 2019} \\
\hline & \multicolumn{2}{|c|}{ Listrik Raw Mill } & \multicolumn{2}{|c|}{ Listrik Kiln } & \multicolumn{2}{|c|}{ Listrik Finish Mill } & \multicolumn{2}{|c|}{ Termal Kiln } \\
\hline \multirow{3}{*}{ Ind 4} & \multirow{3}{*}{$-R p$} & $2.848 .271 \mathrm{kWh}$ & \multirow{3}{*}{ Rp } & $-544.645 \mathrm{kWh}$ & \multirow{3}{*}{$\mathrm{Rp}$} & $-795.673 \mathrm{kWh}$ & \multicolumn{2}{|c|}{ 2.675.411.973 Kcal } \\
\hline & & 2.839.725.809 & & 543.011 .525 & & 793.285 .927 & $-R p$ & 325.702 .327 \\
\hline & & OROS & & HEMAT & & HEMAT & & BOROS \\
\hline \multirow{3}{*}{ Ind 5} & \multirow{3}{*}{$\mathrm{Rp}$} & $-890.473 \mathrm{kWh}$ & \multirow{3}{*}{$\mathrm{Rp}$} & $-1.433 .130 \mathrm{kWh}$ & \multirow{3}{*}{$-R p$} & $606.394 \mathrm{kWh}$ & \multicolumn{2}{|c|}{$-4.610 .415 .627 \mathrm{Kcal}$} \\
\hline & & 887.801 .369 & & 1.428 .830 .243 & & 604.574 .880 & $\mathrm{Rp}$ & 561.267 .989 \\
\hline & & EMAT & & HEMAT & & 3OROS & & HEMAT \\
\hline \multirow{3}{*}{ Ind 6} & \multirow{3}{*}{$\mathrm{Rp}$} & 2.706.274 kWh & \multirow{3}{*}{$\mathrm{Rp}$} & $-1.825 .316 \mathrm{kWh}$ & \multirow{3}{*}{$-R p$} & $415.466 \mathrm{kWh}$ & \multicolumn{2}{|c|}{$-11.742 .302 .257 \mathrm{Kcal}$} \\
\hline & & 2.698.155.422 & & 1.819 .839 .662 & & 414.219.606 & $\mathrm{Rp}$ & 1.429.497.666 \\
\hline & & EMAT & & HEMAT & & 3OROS & & HEMAT \\
\hline \multirow{3}{*}{ Total Saving } & \multirow{3}{*}{$\mathrm{Rp}$} & $-748.476 \mathrm{kWh}$ & \multirow{3}{*}{$\mathrm{Rp}$} & $-3.803 .091 \mathrm{kWh}$ & \multirow{3}{*}{$-R p$} & $226.187 \mathrm{kWh}$ & \multicolumn{2}{|c|}{$-13.677 .305 .910 \mathrm{Kcal}$} \\
\hline & & 746.230 .982 & & 3.791 .681 .430 & & 225.508 .559 & $\mathrm{Rp}$ & 1.665 .063 .328 \\
\hline & & EMAT & & HEMAT & & 3OROS & & HEMAT \\
\hline
\end{tabular}

Tabel 4

Saving Energi Listrik dan Termal Level 1 untuk Pabrik Indarung 4, 5 dan 6

\begin{tabular}{|c|c|c|c|c|c|c|}
\hline PLANT & \multicolumn{2}{|c|}{ ENERGI LISTRIK } & \multicolumn{2}{|c|}{ ENERGI TERMAL } & \multicolumn{2}{|r|}{ TOTAL } \\
\hline Ind 4 & $-R p$ & $\begin{array}{l}1.507 .952 \mathrm{kWh} \\
1.503 .428 .357 \\
\text { BOROS }\end{array}$ & $\begin{array}{r}2.6 \\
-R p \\
\end{array}$ & $\begin{array}{l}75.411 .973 \mathrm{Kcal} \\
325.702 .327 \\
\text { BOROS }\end{array}$ & $-R p$ & $\begin{array}{l}1.829 .130 .684 \\
\text { BOROS }\end{array}$ \\
\hline Ind 5 & $\mathrm{Rp}$ & $\begin{array}{l}-2.323 .602 \mathrm{kWh} \\
2.316 .631 .612 \\
\text { НЕMAT }\end{array}$ & $\begin{array}{l}-4.6 \\
R p\end{array}$ & $\begin{array}{l}10.415 .627 \mathrm{Kcal} \\
561.267 .989 \\
\text { HEMAT }\end{array}$ & $\mathrm{Rp}$ & $\begin{array}{l}2.877 .899 .601 \\
\text { HЕМАТ }\end{array}$ \\
\hline Ind 6 & $\mathrm{Rp}$ & $\begin{array}{l}-4.325 .380 \mathrm{kWh} \\
4.312 .403 .853 \\
\text { HEMAT }\end{array}$ & $\begin{array}{l}-11.7 \\
R p\end{array}$ & $\begin{array}{l}42.302 .257 \mathrm{Kcal} \\
1.429 .497 .666 \\
\text { HEMAT }\end{array}$ & $\mathrm{Rp}$ & $\begin{array}{l}5.741 .901 .519 \\
\text { HЕMAT }\end{array}$ \\
\hline Total Saving & $\mathrm{Rp}$ & $\begin{array}{l}-5.141 .030 \mathrm{kWh} \\
5.125 .607 .108 \\
\text { НЕMAT }\end{array}$ & $\begin{array}{l}-13.6 \\
\mathrm{Rp}\end{array}$ & $\begin{array}{l}77.305 .910 \mathrm{Kcal} \\
1.665 .063 .328 \\
\text { HEMAT }\end{array}$ & $\mathrm{Rp}$ & $\begin{array}{l}6.790 .670 .436 \\
\text { HЕМАТ }\end{array}$ \\
\hline
\end{tabular}

Tabel 5

Total Energi yang berhasil di hemat dalam satuan TOE

\begin{tabular}{|l|r|r|r|}
\hline \multicolumn{1}{|c|}{ Tipe Energi } & Satuan Energi & Dalam Mcal & \multicolumn{1}{|c|}{ Dalam TOE } \\
\hline ENERGI LISTRIK & $5.141 .030 \mathrm{kWh}$ & 4.421 .286 & 442 \\
\hline ENERGI TERMAL & $13.677 .305 .910 \mathrm{Kcal}$ & 13.677 .306 & 1.368 \\
\hline \multicolumn{2}{|r|}{ TOTAL ENERGI YANG DIHEMAT SEBESAR } & 1.810 \\
\hline
\end{tabular}

Berdasarkan hasil perhitungan yang ditampilkan pada tabel diatas dapat dilihat bahwa tidak semua equipment dan pabrik berhasil yang berhasil dalam menurunkan konsumsi Energi. dapat kita lihat pada pabrik Indarung 4 untuk pemakaian energi listrik di equipment Raw Mill mengalami losses atau pemborosan energi listrik sebesar $\mathrm{Rp}$
2,83 miliar dan losses untuk energi termal sebesar Rp 325 juta. Sedangkan untuk equipment finish mill terjadi losses untuk dua pabrik, yaitu pabrik Indarung 5 sebesar Rp 604 juta dan Indarung 6 sebesar Rp 414 juta.

Walaupun ada beberapa losses yang terjadi tetapi jika dihitung secara total terjadi penghematan yang cukup 
besar Rp 6,79 miliar atau sebesar 0,172\% dari nilai COGM (cost of good manufacture) PT Semen Padang berdasarkan RKAP 2019. Oleh karena itu dapat disimpulkan bahwa dengan implementasi dari sistem manajemen energi mendukung cost leadership strategy PT Semen padang

\section{PENUTUP}

Penerapan sistem manajemen energi di PT Semen Padang baru berjalan kurang dari setahun, namun sudah menunjukan hasil yang mengembirakan, yaitu mampu mengurangi pemakaian energi listrik $5.141 .030 \mathrm{kWh}$ atau setara Rp 5,12 miliar dan mengurangi konsumsi energi termal sebesar 13.677.305.910 Kcal jika dikonversi ke rupiah sebsar Rp 1,66 miliar. Jika ditotalkan maka dengan implementasi sistem manajemen energi, PT Semen Padang berhasil menghemat sebesar Rp 6,79 miliar.

Berdasarkan hasil pembahasan dan analisa data yang sudah dilaksanakan didapat kesimpulan bahwa penerapan sistem manajemen energi di PT Semen Padang sangat berkontribusi dalam mengurangi konsumsi pemakaian energi dalam memproduksi semen. Sehingga implementasi dari sistem manajemen energi ini mendukung cost leadership strategy yang telah dirancang oleh perusahaan yang tertuang didalam Rencana Jangka Panjang PT Semen Padang.

Dalam melaksanakan penelitian ini peneliti menemukan banyak hal yang berkaitan dengan pengelolaan energi harus dibenahi agar perusahaan mampu bersaing dengan pabrik semen lainnya, yaitu : a. Implementasi sistem manajemen energi ini belum optimal dilakukan karena masih banyak karyawan dan stakeholder lainnya yang belum memiliki wawasan yang cukup akan pentingnya pengelolaan energi yang efektif dan efesien. Oleh karena itu pihak SDM dan top manajemen harus memikirkan agar kompetensi karywan akan wawasan energi meningkat.

b. Banyak equipment di PT Semen Padang ini masih memakai teknologi yang usang dan tidak hemat energi, oleh karena itu perlu dianalisis secara komprehensif apakah perlu melakukan investasi untuk mengganti equipment tersebut dengan produk baru yang lebih hemat energi.

c. Dalam implementasi sistem manajemen energi ini sangat dipengaruhi banyak faktor seperti faktor politik, sosial, faktor alam dan faktor peralatan. Khusus faktor peralatan perlu di fokuskan lebih karena faktor tersebut bisa kita kontrol dan atur sehingga implementasi manajemen energi ini bisa optimal. Caranya dengan meningkatkan kualitas perawatan mesin, melakukan cek berkala, memilih material yang handal dan menjalankan peralatan sesuai dengan prosedur agar peralatan lebih awet

d. Perlunya komitmen dari top manajemen. Implementasi sistem manajemen ini akan sia-sia apabila tidak adanya dukungan dari top manajemen. Karena sistem manajemen di PT Semen Padang masih baru maka perlu dukungan penuh dari top manajemen agar 
program manajemen energi ini bisa dengan sempurna di implementasikan

Peneliti menyadari bahwa hasil yang ditemukan memiliki sejumlah kekurangan dan kelemahan yang disebabkan adanya keterbatasan yang dimiliki, Adapun keterbatasan tersebut antara lain keterbatasan data karena adanya data yang diperlukan bersifat rahasia sehingga ada sebagian data yang ditampilkan hanya garis besarnya saja. Selain itu dalam menganalisa penghematan yang ada melalui implementasi sistem manajemen energi ini hanya fokus pada proses pembuatan semen di area pabrik saja tidak termasuk proses pertambangan dan proses packing dan distribusi. Dan keterbatasan lain pada penelitian ini adalah durasi yang singkat. Dikarenakan sistem manajemen energi yang terbentuk di PT Semen Padang ini baru berusia sekitar enam bulan jadi implementasi tidak bisa dilakukan secara optimal dan dilakukan di seluruh pabrik.

\section{DAFTAR PUSTAKA}

Arthur A. Thompson, M. A. (2016). Crafting and executing strategy: the quest for competitive advantage, concepts and readings. New York: McGraw-Hill Education.

Barney L. Capehart, W. C. (2006). Guide to energy management. United States of America: The Fairmont Press, Inc.

Carlos Alvarez, G. A. (2004). Assessment and simulation of the responsive demand potential in end-user facilities: application to a university customer. Power System, 1223-1231.

Catherine Cooremans, A. S. (2019). Energy Management. Energy Management: a key driver of energy-efficiency investment?, 4.

Chen, C. H. (2010). Environmental impact of cement production: detail of the different processes and cement plant variability evaluation. Journal of Cleaner Production, 18 (5), 478-485.

Dewan Energi Nasional, S. J. (2017). Buku Ketahanan Energi Indonesia 2017. Jakarta: Dewan Energi Nasional.

Energi, D. J. (2018). Perkembangan dan status manajemen energi pada sektor industri dan bangunan. Surabaya.

Fred R. David, F. R. (2017). Strategic Management Concept and Cases A Competitive AdvAntAge ApproACh. essex: Pearson education Limited.

Galitsky, E. W. (2008). Energy Efficiency Improvement and Cost Saving Opportunities Cement Making. California: U.S. Environmental Protection Agency.

Hasanbeigi, A. M. (2010). The CO2 abatement cost curve for the Thailand cement industry. Journal of Cleaner Production , 18 (15), 1509-1518.

Hawksworth, J. (2008). The World in 2050 - Can Rapid Global Growth be Reconciled with Moving to a Low Carbon Economy? London.

ISBI, P. (2018). audit energi (listrik) semen indonesia group -2018. Jakarta. 
Johanna Lehne, F. P. (2018). Making Concrete Change: Innovation in Low-carbon Cement and Concrete. Cambridge: Chatham House.

Kleiner, D. P. (2015). Management Research News. Competitive advantage in global industries, 111-117.

Kumar, R. P. (2016). Value chain. a conceptual framework, 74-77.

L.A. Tiago, C. A. (2017). Strategies to make renewable energy sourcesEnergy Strategy, 121-126.

(2018). Laporan Tahunan. Jakarta: PT Semen Indonesia.

Maryanne M. Mowen, D. R. (2012). Cornerstones of managerial accounting.

MIGAS, D. (2016). Laporan Tahunan SKK Migas.

Porter, M. E. (1998). Competitive Advantage Creating and Sustaining Superior Performance. New York: The Free Press.
Sartono, A. (2012). Manajemen Keuangan: Teori dan Aplikasi. Yogyakarta: BPFE Yogyakarta.

Sarvino, F. (2017). Rancangan Penilaian Sistem Manajemen Energi di PT Semen Padang Dengan Menggunakan Pendekatan Integrasi ISO 50001, Sistem Manajemen Semen Padang (SMSP) dan Permen ESDM No. 14 Tahun 2012. Padang: Universitas Andalas.

Schuster, C. D. (2012). Competitive advantage of German renewable energy firms in India and China. International Journal of Emerging Markets, 191 - 214.

SMSP. (2018). Pedoman Sistem Manajemen Semen Padang. Padang.

Syamsuddin, L. (2011). Manajemen Keuangan Perusahaan. Jakarta: CV Rajawali.

Syed Zagam Abbasa, A. K. (2018). Energy Strategy Reviews. Energy management in South Asia, 1. 